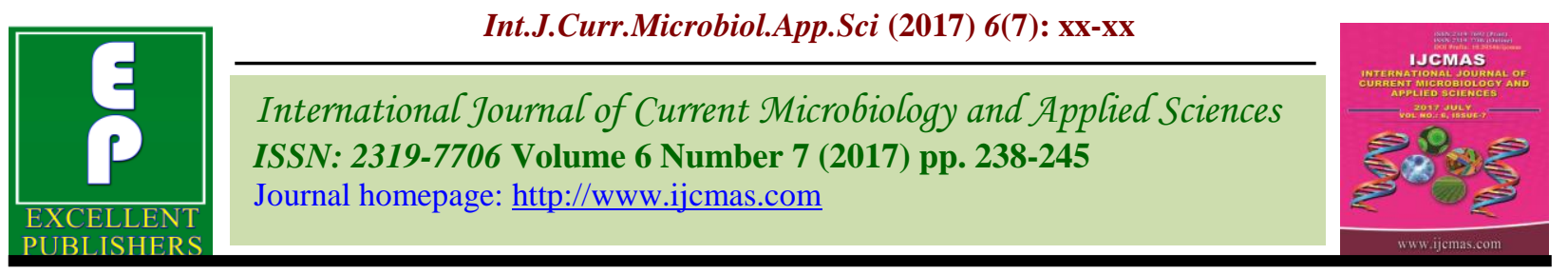

Original Research Article

https://doi.org/10.20546/ijcmas.2017.607.028

\title{
Knowledge, Attitude, Practice Study on Awareness of Antibiotic Stewardship among Healthcare professionals in a Tertiary Care Hospital in Delhi
}

\author{
Malvika Singh $^{1^{*}}$ and Anil Kumar Singh ${ }^{2}$ \\ ${ }^{1}$ Department of Microbiology, University College of Medical Sciences, Delhi, India \\ ${ }^{2}$ Rajiv Gandhi Super Speciality Hospital, Delhi, India \\ *Corresponding author
}

\section{A B S T R A C T}

Keywords

Antimicrobial

Stewardship,

AMR.

Article Info

Accepted:

04 June 2017

Available Online:

10 July 2017
Antimicrobial stewardship has been defined as "the optimal selection, dosage, and duration of antimicrobial treatment that results in the best clinical outcome for the treatment or prevention of infection, with minimal toxicity to the patient and minimal impact on subsequent resistance. Rapid development of antimicrobial agents came with a cost antimicrobial resistance. Physicians play an important role in the fight against antimicrobial resistance by their rational practices in usage of antimicrobials and by educating the society regarding usage of antibiotics and its consequences of developing resistance. Hence, cross sectional survey was conducted to understand knowledge, attitude and practice of resident doctors regarding the antibiotic stewardship practices, at a tertiary care hospital, Delhi, India, which will guide us in developing strategies for effective implementation of such programmes. To assess the knowledge attitude and practice in resident doctors on antibiotic stewardship programme at a tertiary care centre. The study was conducted by a survey of preformed questions on knowledge, attitude and practice in antibiotic stewardship practices among 80 resident doctors at Tertiary care hospital, Delhi, India from March 2016 to April 2016. In this study 44.6\% of the participants were females and $55.4 \%$ were males; $90 \%$ of the participants knew about the advantages of having hospital antibiotic policy; $78.7 \%$ feel confident about their knowledge and practice in the area of antimicrobial prescribing; $86.2 \%$ feel that hospital antibiotic policy is useful in reducing AMR; $83.7 \%$ people know that combination of antibiotics can prevent development of AMR; 70\% feel that microbiologist should be consulted when required about antibiotic prescription; $87.5 \%$ had a copy of antibiotic policy of the hospital; $16.2 \%$ do not practice consulting the senior physician before prescribing higher antibiotics; $72.5 \%$ follows de-escalation in their practice; $86.2 \%$ implement antibiotic policy in their practice? The study concludes that there is a need for approach that includes implementation of antibiotic policy and to plan for an effective undergraduate teaching programme regarding antibiotic resistance and prescription which can improve the quality of antibiotic prescription and thereby minimizing the antibiotic resistance.

\section{Introduction}

Antimicrobial stewardship has been defined as "the optimal selection, dosage, and duration of antimicrobial treatment that results in the best clinical outcome for the treatment or prevention of infection, with minimal toxicity to the patient and minimal impact on subsequent resistance (Gerding, 2001)". 
In the early days of antibiotics, booming drug development meant that even when resistance developed, a new drug was always available to treat the increasingly resistant bacteria. Fourteen new classes of antibiotics were introduced between 1935 and 2003. However, rapid development of antimicrobial agents came with a cost - antimicrobial resistance. Physicians play an important role in the fight against antimicrobial resistance by their rational practices in usage of antimicrobials and by educating the society regarding usage of antibiotics and its consequences of developing resistance.

There is growing evidence that hospital based programmes, known as "Antibiotic Stewardship Programmes" which are dedicated to optimize antibiotic use in hospital, can guide clinicians on antibiotic use, improve the frequency of correct prescribing, improve quality of care to patients, reduce development of drug resistance/ treatment failure, prevention of adverse effects of drugs, curb the expenses on unnecessary drug usage.

Hence, cross sectional survey was conducted to understand knowledge, attitude and practice of resident doctors regarding the antibiotic stewardship practices, at a tertiary care hospital, Delhi, India, which will guide us in developing strategies for effective implementation of such programmes.

To assess the knowledge attitude and practice in resident doctors on antibiotic stewardship programme at a tertiary care centre.

\section{Materials and Methods}

\section{Study population}

The study was conducted by a survey of preformed questions on knowledge, attitude and practice in antibiotic stewardship practices among 80 resident doctors at
Tertiary care hospital, Delhi, India from March 2016 to April 2016.

\section{Study tool}

It was a cross sectional, preformed questionnaire based survey of doctors. Need for the study and confidentiality were explained to the participating doctors. The first section of the questionnaire involves the demographic data of the participant such as age, sex, address and educational qualification.

The second section of the questionnaire involves questions to assess the knowledge of the participant about the antibiotic usage and resistance. The questions in this section should be answered as 'yes' or 'no'. The third section of the questionnaire consists of questions to study the attitude of the participants towards the antibiotic use and resistance. The fourth section of the questionnaire consists of questions to evaluate the practice of antibiotic prescription.

\section{Study procedure}

Objectives of the study were explained to the participants and their willingness to participate in the study was obtained. After which the questionnaire was distributed and they were asked to complete it anonymously. Completed questionnaires were collected and analyzed. They were assured confidentiality of the identity throughout and the right to know the results of the study after the completion of the same.

Questionnaire used was customized and formed on knowledge, attitude, practice and opinions on effectiveness of antibiotic policy after reviewing the relevant literature and the questionnaires used in similar studies (Huang et al., 2013; Mahajan et al., 2014; Ganesh et al., 2014; Jorak, 2014). It had questions, 10 for knowledge, attitude and practice each. It 
was verified and authenticated by subject experts. The residents were then guided with the appropriate approach towards rational use of antibiotics.

\section{Inclusion criteria}

- Interns

- Junior residents

- Senior residents

\section{Exclusion criteria}

- Doctors not willing to participate

- Doctors part of hospital infection control team

- Doctors from clinical pharmacology

- Doctors from clinical microbiology

- Doctors who are part of therapeutic committee, antibiotic auditing etc who can bias the results

- Doctors who fail to return filled in forms within stipulated time

\section{Results and Discussion}

In our study $44.6 \%$ of the participants were females and $55.4 \%$ were males.

\section{Knowledge assessment}

90\% of the participants knew about the advantages of having hospital antibiotic policy. $78.7 \%$ feel confident about their knowledge and practice in the area of antimicrobial prescribing. $81.2 \%$ were aware that patients with common cold symptoms does not need antibiotic treatment.87.5\% knew that the efficacy is not better if the antibiotics are newer and costly. 91.25\% people feel that the drugs should not be overprescribed. $83.7 \%$ feel that antibiotics should not be purchased without prescription. $71.2 \%$ feel sample for culture should be taken before starting antibiotics. $73.7 \%$ were aware of antibiotic escalation and de-escalation. Only $58.7 \%$ were aware that resistant drug can become sensitive. $72.5 \%$ feel that higher antibiotics use should be reserved and could be used only after authorization from senior physician (Table 1).

\section{Attitude assessment}

$86.2 \%$ feel that hospital antibiotic policy is useful in reducing AMR. 83.7\% people know that combination of antibiotics can prevent development of AMR. $70 \%$ feel that microbiologist should be consulted when required about antibiotic prescription. 31.2\% had attitude of doing culture and sensitivity test in all infections, $88.7 \%$ had attitude of taking sample for culture before starting antibiotics. $58.7 \%$ had attitude to de-esclate to lower class sensitive drugs when the current higher class drug is also sensitive. $33.7 \%$ think irrational practice locally will not matter for global resistance development. Only $11.2 \%$ feel that dispensing of antibiotics over the counter for minor ailments by pharmacists should be allowed. $87.5 \%$ had an attitude of educating the patients regarding rational use of antibiotics. $18.7 \%$ feel that cost should be considered before starting the treatment (Table 2).

\section{Practice assessment}

$87.5 \%$ had a copy of antibiotic policy of the hospital. $16.2 \%$ do not practice consulting the senior physician before prescribing higher antibiotics.72.5\% follows de-escalation in their practice.86.2 \% implement antibiotic policy in their practice. $70 \%$ agreed that many times $(3 / 5)$ they have to escalate to higher antibiotics in spite present lower antibiotic is sensitive. $56.2 \%$ said that they don't take help of pharmacologist/clinical microbiologist to choose drugs. $83.7 \%$ educate the patients on rational use of antibiotics. $70 \%$ send sample for culture and sensitivity in every case before starting antibiotics. $15 \%$ are not sure about choosing the appropriate dose of antibiotics. $72.5 \%$ are sure about choosing the combination of antibiotics (Table 3 ). 
Graph.1 Showing percentage of male and female participants

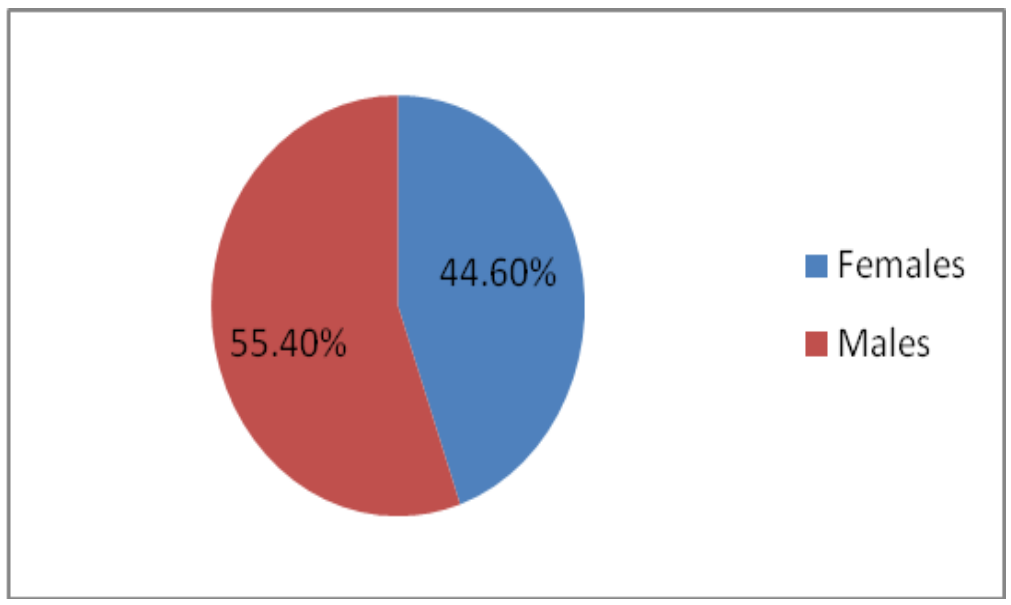

Graph.2 Showing percentage of questions answered in knowledge assessment in yes/no pattern

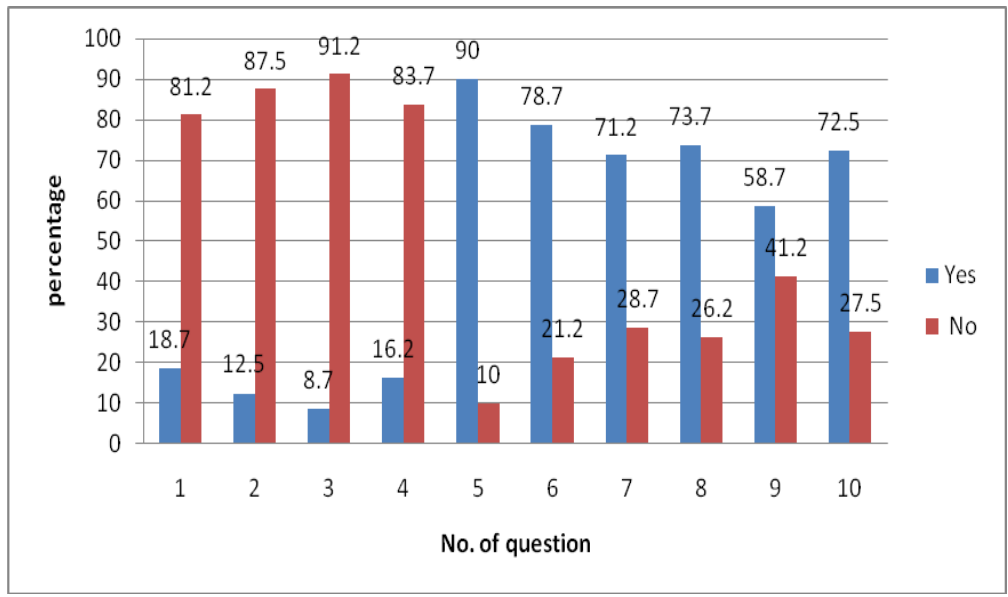

Graph.3 Showing percentage of attitude assessment

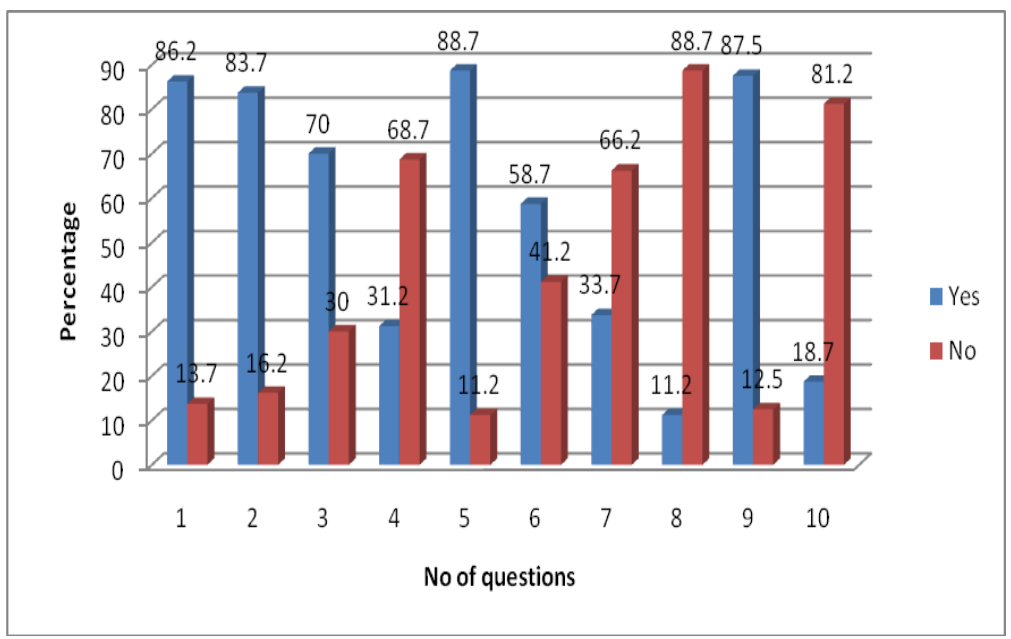


Graph.4 Showing practice assessment

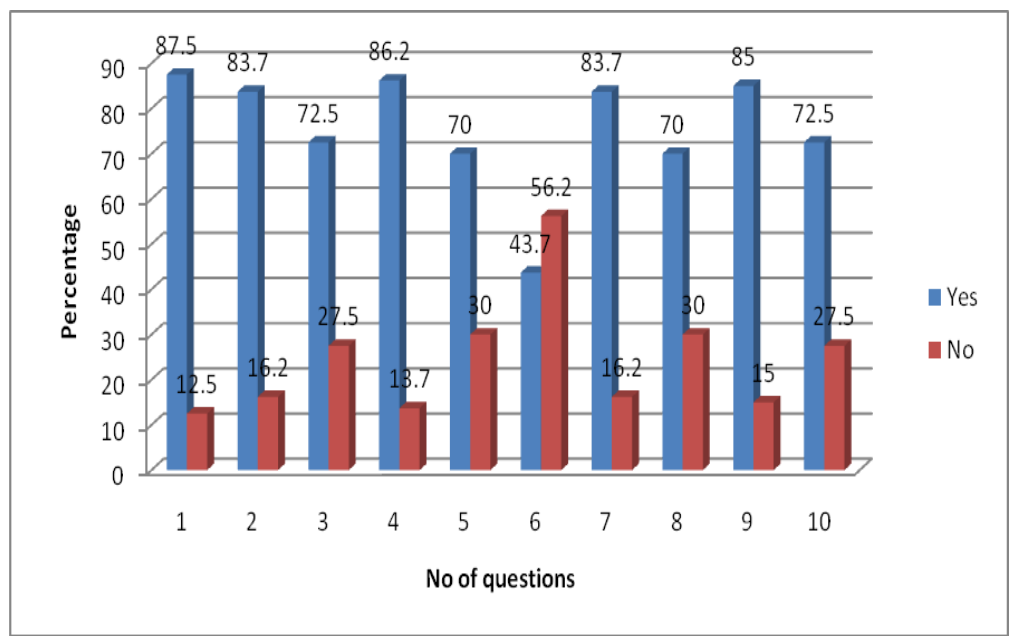

Table.1 Knowledge assessment

\begin{tabular}{|l|l|l|}
\hline Statement & $\begin{array}{l}\text { Yes (N=80) } \\
\mathbf{n}(\mathbf{\%})\end{array}$ & $\begin{array}{l}\text { No (N=80) } \\
\mathbf{n}(\mathbf{\%})\end{array}$ \\
\hline $\begin{array}{l}\text { Patients with common cold symptoms need } \\
\text { antibiotic treatment }\end{array}$ & $15(18.7 \%)$ & $65(81.2 \%)$ \\
\hline $\begin{array}{l}\text { The efficacy is better if the antibiotics are newer and } \\
\text { more costly? }\end{array}$ & $10(12.5 \%)$ & $70(87.5 \%)$ \\
\hline $\begin{array}{l}\text { It is always better to over-prescribe antibiotics than } \\
\text { under-prescribe? }\end{array}$ & $07(8.7 \%)$ & $73(91.2 \%)$ \\
\hline $\begin{array}{l}\text { Everyone should be able to buy antibiotics without a } \\
\text { prescription? }\end{array}$ & $13(16.2 \%)$ & $67(83.7 \%)$ \\
\hline $\begin{array}{l}\text { Are you aware of the advantage of having antibiotic } \\
\text { policy in the hospital? }\end{array}$ & $72(90.0 \%)$ & $08(10.0 \%)$ \\
\hline $\begin{array}{l}\text { You feel confident about your knowledge and } \\
\text { practice in the area of antimicrobial prescribing? }\end{array}$ & $63(78.7 \%)$ & $17(21.2 \%)$ \\
\hline $\begin{array}{l}\text { Sample for culture and sensitivity should be taken } \\
\text { before starting antibiotic }\end{array}$ & $57(71.2 \%)$ & $23(28.7 \%)$ \\
\hline $\begin{array}{l}\text { Are you aware of antibiotic escalation and de } \\
\text { escalation }\end{array}$ & $59(73.7 \%)$ & $21(26.2 \%)$ \\
\hline Resistant drug can become sensitive again & $47(58.7 \%)$ & $33(41.2 \%)$ \\
\hline $\begin{array}{l}\text { Higher antibiotics use should be reserved and could } \\
\text { be used only after authorization from senior } \\
\text { Physician. }\end{array}$ & $58(72.5 \%)$ & $22(27.5 \%)$ \\
\hline
\end{tabular}


Table.2 Attitude assessment

\begin{tabular}{|l|l|l|l|}
\hline S.No & Question & Yes (N=80) n\% & $\begin{array}{l}\text { No (N=80) } \\
\mathbf{n} \%\end{array}$ \\
\hline 1. & $\begin{array}{l}\text { Hospital Antibiotic policy is useful in reducing } \\
\text { AMR }\end{array}$ & $69(86.2 \%)$ & $11(13.7 \%)$ \\
\hline 2. & $\begin{array}{l}\text { Combination of antibiotics can prevent } \\
\text { development of AMR }\end{array}$ & $67(83.7 \%)$ & $13(16.2 \%)$ \\
\hline 3. & $\begin{array}{l}\text { Microbiologist should be consulted when required } \\
\text { about Antibiotic prescription }\end{array}$ & $56(70 \%)$ & $24(30 \%)$ \\
\hline 4. & $\begin{array}{l}\text { Culture and sensitivity test should be done in all } \\
\text { infections }\end{array}$ & $25(31.2 \%)$ & $55(68.7 \%)$ \\
\hline 5. & $\begin{array}{l}\text { Sample for culture should be sent before starting } \\
\text { antibiotics }\end{array}$ & $71(88.7 \%)$ & $9(11.2 \%)$ \\
\hline 6. & $\begin{array}{l}\text { De-escalation of drugs from higher to lower class } \\
\text { is beneficial in reducing AMR }\end{array}$ & $47(58.7 \%)$ & $33(41.2 \%)$ \\
\hline 7. & $\begin{array}{l}\text { Irrational practice locally will not matter for } \\
\text { global resistance development }\end{array}$ & $27(33.7 \%)$ & $53(66.2 \%)$ \\
\hline 8. & $\begin{array}{l}\text { Dispensing of antibiotics over the counter for } \\
\text { minor ailments by pharmacists should be allowed }\end{array}$ & $9(11.2 \%)$ & $71(88.7 \%)$ \\
\hline 9. & $\begin{array}{l}\text { Patients should be educated regarding Rational } \\
\text { use of antibiotics }\end{array}$ & $70(87.5 \%)$ & $10(12.5 \%)$ \\
\hline 10. & $\begin{array}{l}\text { Cost should be considered before starting the } \\
\text { treatment }\end{array}$ & $15(18.7 \%)$ & $65(81.2 \%)$ \\
\hline
\end{tabular}

Table.3 Practice assessment

\begin{tabular}{|c|c|c|c|}
\hline S.No & Question & $\begin{array}{l}\text { Yes }(\mathrm{N}=80) \\
\text { n\% }\end{array}$ & No $(\mathrm{N}=80) \mathrm{n} \%$ \\
\hline 1. & $\begin{array}{l}\text { Do you have a copy of Antibiotic policy of your } \\
\text { hospital? }\end{array}$ & $70(87.5 \%)$ & $10(12.5 \%)$ \\
\hline 2. & $\begin{array}{l}\text { Do you practice consulting senior physician before } \\
\text { prescribing higher antibiotics? }\end{array}$ & $67(83.7 \%)$ & $13(16.2 \%)$ \\
\hline 3. & Do you follow de-escalation practices? & $58(72.5 \%)$ & $22(27.5 \%)$ \\
\hline 4. & Do you implement antibiotic policy in your practice? & $69(86.2 \%)$ & $11(13.7 \%)$ \\
\hline 5. & $\begin{array}{l}\text { Do you escalate to higher antibiotic treatment inspite } \\
\text { of lower antibiotics being sensitive? }\end{array}$ & $56(70 \%)$ & $24(30 \%)$ \\
\hline 6. & $\begin{array}{l}\text { Do you take help ofpharmacologist/clinical } \\
\text { microbiologist to choose drugs? }\end{array}$ & $35(43.7 \%)$ & $45(56.2 \%)$ \\
\hline 7. & Do you educate the patients on rational antibiotic use? & $67(83.7 \%)$ & $13(16.2 \%)$ \\
\hline 8. & $\begin{array}{l}\text { Do you send sample for culture \& sensitivity test in } \\
\text { every case before starting antibiotics }\end{array}$ & $56(70 \%)$ & $24(30 \%)$ \\
\hline 9. & $\begin{array}{l}\text { Are you sure about choosing the appropriate dose of } \\
\text { antibiotics? }\end{array}$ & $68(85 \%)$ & $12(15 \%)$ \\
\hline 10. & $\begin{array}{l}\text { Are you sure about choosing the combination of } \\
\text { antibiotics when necessary? }\end{array}$ & $58(72.5 \%)$ & $22(27.5 \%)$ \\
\hline
\end{tabular}


The study was conducted to evaluate the knowledge, attitude and practice of resident doctors towards antibiotic resistance and prescription. Most of the participants in our study were aware of this fact that Antibiotic resistance has become an important and serious public health problem. A similar response was observed in a study conducted by Jorak et al., (2014). Majority of people were aware of the fact that indiscriminate use of antimicrobial agents' results in the bacterial resistance. Similarly, another study conducted in China has also reported that majority of the participants including medical students were aware of the fact that abuse of antibiotics is a main cause for antibiotic resistance (Huang et al., 2013).

Majority of the participants $(81.2 \%)$ in our study felt that antibiotics are not required to treat the symptoms of common cold. A similar response was also observed in another study (Jorak, 2014). However, according to the study of Hueng et al., (2013) the majority of the participants had a belief that antibiotics can speed up recovery of common cold, cough and a number of other related illnesses arising from viral infections. This wrong perception can result in increased usage of antibiotics, which in turn can result in an increase in antibiotic resistance (Chatterjee et al., 2015). Therefore the need for educational intervention is necessary. It becomes difficult to change the established beliefs after the doctors become qualified (Simpson et al., 2007). Hence, it is important to educate young doctors about antibiotic resistance and its prescription during their training. Case-based scenarios teaching can involve small group activities involving the management of common infections where antibiotics are often misused. Also, the principles of antibiotic stewardship can be highlighted. The curriculum should also include skills to communicate with the patients especially in uncertain diagnosis situation which helps reduce the unnecessary prescription. Thus, our study has generated information about the knowledge, attitude and practice of interns towards antibiotic resistance and prescription which helps us to plan for an efficient and effective curriculum regarding the same.

The study concludes that there is a need for approach that includes implementation of antibiotic policy and to plan for an effective undergraduate teaching programme regarding antibiotic resistance and prescription which can improve the quality of antibiotic prescription and thereby minimizing the antibiotic resistance.

\section{References}

Chatterjee, D., Sen, S., Begum, S.A., Adhikari, A., Hazra, A., Das, A.K. 2015. A questionnaire based survey to ascertain the views of clinicians regarding rational use of antibiotics in teaching hospitals of Kolkata. Indian J. Pharmacol., 47: 105-8.

Ganesh, M., Sridevi, S.A., Paul, C.M. 2014. Antibiotic use Among Medical and Para Medical Students: Knowledge, Attitude and its Practice in a Tertiary Health Care Centre in Chennai- a Scientific Insight. Int. J. Sci. Res., 3(7): 332-5.

Gerding, D.N. 2001. The search for good antimicrobial stewardship. Jt. Comm. J. Qual. Improv., 27(8): 403-404.

Huang, Y., Gu, J., Zhang, M., Ren, Z., Yang, W., Chen, Y. 2013. Knowledge, attitude and practice of antibiotics: a questionnaire study among 2500 Chinese students. BMC Med. Edu., 13:163.

Jorak, A. 2014. A Cross Sectional Study on Knowledge, Attitude and Practice of Medical Students towards Antibiotic Resistance and its Prescription, Iran. Adv. Environ. Biol., 8(17): 675-81. 
Mahajan, M., Dudhgaonkar, Deshmukh, S. 2014. A Questionnaire based Survey on the Knowledge, Attitude and Practises about Antimicrobial Resistance and Usage among the Second year MBBS Students of a Teaching tertiary care
Hospital in Central India. Int. $J$. Pharmacol. Res., 4(4): 175-9.

Simpson, S.A., Wood, F., Butler, C.C. 2007. General Practitioners' perceptions of antimicrobial resistance: a qualitative study. J. Antimicrob. Chemother., 59(2): 292-6.

\section{How to cite this article:}

Malvika Singh and Anil Kumar Singh. 2017. Knowledge, Attitude, Practice Study on Awareness of Antibiotic Stewardship among Healthcare Professionals in a Tertiary Care Hospital in Delhi. Int.J.Curr.Microbiol.App.Sci. 6(7): 238-245.

doi: https://doi.org/10.20546/ijcmas.2017.607.028 